\title{
A Educação Inclusiva na Rede Municipal em Juazeiro da Bahia
}

\author{
Francisco Carlos Aguiar $^{\text {; }}$ Leide Jane Carvalho Ferreira ${ }^{2}$; Adilton Marques Rosa ${ }^{3}$; \\ Willian Carvalho Ferreira ${ }^{4}$; Lucimara Araújo Campos Alexandre ${ }^{5}$.
}

\begin{abstract}
Resumo: O presente estudo, trata da inclusão das pessoas com deficiência, na rede municipal na cidade de Juazeiro da Bahia. Em vista disto, ele irá identificar quais as principais barreiras encontradas para a integração das pessoas com deficiência, em uma de sala na rede pública de ensino. Os procedimentos metodológicos para constituição dos dados da pesquisa, foi de natureza quali-quantitativa e exploratória, mediante um questionário com perguntas abertas, e um outro questionário com perguntas fechadas, complementando mais o estudo pesquisado. A resultante dos dados, mostra que tanto os familiares como os docentes, reconhecem que as barreiras existem relacionados as pessoas com deficiência, mas eles têm buscados uma interação entre ambos para integrar a inclusão das pessoas com deficiência, em uma sala de aula na rede de ensino.
\end{abstract}

Palavras chaves: inclusão, barreiras, sala de aula e integração.

\section{Inclusive Education in the Municipal Network of Juazeiro da Bahia}

Abstract: The present study deals with the inclusion of persons with disabilities, in the municipal network in the city of Juazeiro in Bahia. In view of this, it will identify the main barriers encountered for the integration of persons with disabilities, in a room in the public schools. The methodological procedures for formation of research data, quantitative and qualitative exploratory nature, by means of a questionnaire with open questions, and another questionnaire with questions closed, complementing more researched study. The resulting data, shows that both her parents as teachers, recognize that there are barriers related to disabled people, but they have fetched an interaction between both to integrate the inclusion of persons with disabilities, in a classroom in the school network.

Key words: inclusion, barriers, and classroom integration.

\section{Introdução}

A Educação Inclusiva é um processo educacional de ensino que engloba todos os alunos com deficiência, permitindo-os a frequentarem a escola, junto com os alunos que não possuem deficiência (GIL, 2005). De acordo com o Decreto $n^{\circ} 3.298$, de 20 de dezembro de

\footnotetext{
${ }^{1}$ Acadêmico em Bacharelado em Administração Pública pela SEAD/Univasf Polo. Juazeiro. Bahia. Brasil. E-mail: aguia.senasp@hotmail.com;

${ }^{2}$ Acadêmica em Bacharelado em Administração Pública pela SEAD/Univasf Polo. Juazeiro. Bahia. Brasil. E-mail: Leide.perfumes@hotmail.com.br;

${ }^{3}$ Acadêmico em Bacharelado em Administração Pública pela SEAD/Univasf Polo. Juazeiro. Bahia. Brasil. E-mail: AdiltonMarquesRosa@yahoo.com;

${ }^{4}$ Acadêmico em Bacharelado em Administração Pública pela SEAD/Univasf Polo. Juazeiro. Bahia. Brasil. E-mail: williamcarvalho.omoral@hotmail.com.

${ }^{5}$ Doutoranda da Fundação Antônio Prudente. Professora Assistente da Univasf. Petrolina. Pernambuco. Brasil. E-mail: lucimara.univasf@gmail.com. 
1999, em seu art. $4^{\circ}$, entende-se que a pessoa com deficiência é a que está integrada nas seguintes categorias: Deficiência Física; Deficiência Auditiva; Deficiência Visual; Deficiência Mental; e Deficiência Múltipla.

No Brasil, a Constituição Federal (1988), em seu artigo 208, inciso III, constitui aos portadores de deficiência direito a um atendimento educacional especializado, de preferência na rede regular de ensino.

Segundo Costa (2011), o sistema regular de ensino não atende as diferenças no aprendizado dos alunos dito normais, mostrando assim, a fragilidade da responsabilidade dos alunos com deficiências em uma sala de aula.

Contudo, Zoía (2006) diz que os profissionais de ensino regular, através de ações educativas, devem buscar atender os alunos com deficiência, de um modo adequado à sua adversidade, pautado no respeito mútuo, para preparação desses educandos no convívio em uma sociedade.

Nesse sentido, Paulon et al. (2005) afirma que um pressuposto frequente nas políticas relativas a inclusão supõe um processo sustentado unicamente pelo professor, no qual o trabalho dele é concebido como responsável pelo seu sucesso ou fracasso. No entanto, é sabido que o professor comprometido com o que faz, deverá ter como alvo principal, o aprendizado do aluno, buscando aprimorar as suas metodologias, com o objetivo de construir conhecimentos e desenvolver novas habilidades. Portanto, para que a inclusão de fato aconteça, faz-se necessário mover diferentes estruturas, partindo do físico, ou seja a escola deverá adaptar-se as necessidades dos alunos, e isso envolve também o currículo, a avaliação, e a formação do professor (CARDOSO; STOBÄUS, 2004).

Corroborando com que foi exposto, a Lei $\mathrm{n}^{\circ} 13.146$ de julho de 2015, instituída como a Lei Brasileira de Inclusão da pessoa com Deficiência (Estatuto da pessoa com deficiência), em seu artigo $1^{\circ}$, assegura e promove ascondições de igualdade, e a execução dos direitos e liberdades fundamentais para as pessoas com deficiência, visando à sua inclusão social e cidadania

Diante disso, a "Inclusão", faz-se pensar em ingresso de oportunidade e qualidade em uma rede educacional de ensino, contextualizada essencialmente em uma escola pública e vivenciada na cultura de uma sociedade. Deste modo, irá pautar coletivamente na vida pública e política participativa de seus membros, valorados aos princípios de igualdade, justiça e 
qualidade, e que concomitantemente irá buscar a dignidade na vida perante todas as pessoas (BOOTH; AINSCOW, 2011).

A dificuldade de modificar a exclusão da educação em questão, resulta em categorizar diferenças (culturais, sociais, psíquicas, físicas dentre outras) entre as pessoas existentes na sociedade que buscam derrubá-las e consolidar a ética com a cidadania, em um modelo de escola inclusiva a todos os alunos, sejam eles normais ou com deficiência (BOOTH; AINSCOW, 2011).

Assim, segundo Paulon et al. (2005), o fato da criança ter uma deficiência mental, não diz nada a respeito do modo como sua estrutura está se processando. Uma pessoa com deficiência mental, assim como uma sem deficiência, pode apresentar uma série muito grande de características psicológicas distintas que vão desde quadros patológicos, como psicose, autismo, até a possibilidade de se constituir como um sujeito de desejo. A determinação dessas diferentes estruturas, esta fundada nas experiências e formas de relação que uma criança estabelece, a partir do lugar que ocupa em sua cultura de origem.

Na educação inclusiva, mesmo combatendo à segregação entre os alunos diferençados entre si, ainda que contenha resistências, o convívio entre esses alunos não traduz a ausência do preconceito na forma da manifestação deles (MIRANDA; GALVÃO FILHO 2012).

Portanto, o empenho ao acesso do aluno com deficiência em uma escola, irá resultar na construção do modelo da escola vigente (escola inclusiva), pautada na qualidade educacional de ensino para todos os alunos, sejam eles normais ou com deficiência, consolidando a ambos o princípio de igualdade e oportunidade entre eles. Diante do que foi exposto, a exclusão e o preconceito serão combatidos, na intenção de construir uma sociedade mais justa e igualitária (CROCHÍK, 2011).

Considerando a complexidade do tema "A Educação Inclusiva na Rede Municipal”, ressalta-se que o termo Inclusão, não está envolvendo só as pessoas que se diz excluídas de uma rede educacional de ensino, mas também, todas as crianças e jovens com ou sem deficiência, independentemente de sua etnia ou classe social. Desta forma, todas as diferenças entre as pessoas envolvidas no contexto devem ser respeitadas visando uma maior integração entre elas, para democratizar o compromisso de respeito aos direitos que abarca todas as pessoas com deficiência, a possibilidade de um processo de aprendizagem e desenvolvimento 
intelectual em uma rede educacional (CONFEDERAÇÃO SOBRE OS DIREITOS DAS PESSOAS COM DEFICIÊNCIA, 2008).

O embasamento teórico da pesquisa apresentada discute a aplicação efetiva acerca da integração dos alunos com deficiência em uma rede de ensino, como também, perante outras pessoas na sociedade.

O presente estudo teve como objetivo descrever como se dá o processo de educação inclusiva na cidade de juazeiro da Bahia, cujos resultados poderão pautar discussões gestoras locais sobre as práticas educativas e o processo de inclusão das pessoas com deficiência em uma sala de aula, além de promover o estímulo e a segurança nas famílias e sociedade para integrar essas pessoas deficientes no meio social, fortalecendo assim o caminho que consolide a cidadania das pessoas com deficiência a frequentar a escola, em uma rede de ensino com qualidade.

\section{Metodologia}

Esta pesquisa científica empregou métodos de natureza quali-quantitativa e exploratória, e foi realizado junto com a (SEDUC) Secretaria de Educação e Juventude, na cidade de Juazeiro Bahia, e mais três escolas (Escola Celso Cavalcante de Carvalho, Escola Terezinha Ferreira de Oliveira e Escola Maria de Lourdes Duarte), da rede municipal de ensino, localizada na mesma cidade.

Creswell (2007), descreve que a aplicação de métodos mistos (quali-quantitativa) de pesquisa nas áreas de ciências humanas e sociais, decorre da necessidade de vincular esses dados. Segundo Gil, (2010), a pesquisa exploratória, proporciona uma maior familiaridade do problema explicitado, como por exemplo: a entrevista e levantamentos bibliográficos.

Para a coleta de dados foram entrevistados 12 participantes, sendo dois funcionários da (SEDUC), a secretaria de educação e sua auxiliar coordenadora e mais 10 professores da rede municipal de ensino, sendo todos da mesma escola, além disso, o critério utilizado para escolha da escola foi trabalhar com educação inclusiva. Todos foram informados sobre o projeto, objetivos e procedimentos metodológicos, e solicitada a assinatura do Termo de 
Consentimento Livre e Esclarecido (TCLE), sendo assegurado o sigilo e a confidencialidade das informações, e a identidade de cada participante da pesquisa.

A coleta de dados se deu por meio de uma entrevista, tendo como instrumento de coleta dois questionários, um com perguntas abertas que abordarão assuntos relacionados às pessoas com deficiência, como: Resistência à inclusão social das pessoas com deficiência; Supressão do preconceito sob a inclusão; Atividades desenvolvidas para pessoas com deficiência; O papel da família relacionado à inclusão; Avaliação do desenvolvimento da pessoa com deficiência; Preparação dos professores e funcionários para lidar com pessoas deficiência; Formação dos professores na área; e Materiais tecnológicos para o desenvolvimento do conhecimento das pessoas com deficiência, além de outro questionário com perguntas fechadas abordando assuntos também relacionados às pessoas com deficiência como: Aquisição do conhecimento, na escola, por parte dos alunos com deficiência; Os alunos com deficiência dificultam a qualidade do ensino; A eficácia da educação inclusiva na cidade de Juazeiro; Escolas ou cursos profissionalizantes na cidade de Juazeiro; e Preconceito e discriminação dos alunos normais em relação aos alunos com deficiência.

O questionário, segundo Marconi e Lakatos (2003), é um instrumento de coleta de dados composta por perguntas ordenadas, por onde devem ser registradas suas respostas, sem a presença do entrevistador. Sendo assim, o questionário de perguntas abertas, fornecerá ao informante, responder perguntas livres, com vocabulário próprio, expressando a opinião dele. Enquanto o questionário de perguntas fechadas ou dicotômicas, são as que oferecerá duas respostas na opção da questão.

\section{Resultados e Discussão}

A apresentação dos resultados e análise dos dados, serão abordados de acordo com o tema em questão. 


\title{
Resistência à inclusão social das pessoas com deficiência
}

\begin{abstract}
Professores. 1. A convivência é quem vai dizer como fazer, ninguém faz curso para ser mãe, simplesmente, é mãe ou professor. Só aprende a trabalhar com as deficiências se conviver com elas, porque a convivência é quem diz.

Secretaria de Educação. 2. Primeiramente começa com a família, quer dizer na maneira que a família trata essas pessoas com deficiência, e a outra resistência seria a própria escola, até porque, alguns anos atrás poucos se ouviam falar na inclusão de pessoas com deficiência em uma sala de aula originado assim, um despreparo dos professores.
\end{abstract}

Observa-se aqui nessa questão, que a convivência é o principal obstáculo encontrado na inclusão das pessoas com deficiência. Diante disso, a resistência ao convívio dessas pessoas com deficiência na educação, pode ser motivada pela falta de conhecimento ou informação da família ou pela falta de capacitação dos professores na escola.

Lipovetsky (2005), diz que uma sociedade diversa, deve oferecer a seus integrantes mais flexibilidade a mudança, por onde uma sociedade que se diz inclusiva, tem a obrigação de abater a resistência, para que essas pessoas se relacionem, eximindo-o do isolamento.

Saad (2003) e Voivodic (2007), afirmam que as escolas devem rever os seus modelos de ensino, aprendizagem e avaliação, para que os familiares dos alunos com deficiência sintam-se seguros no relacionamento escola, professor e aluno.

\section{Supressão do preconceito sob a inclusão}

Professores. 1. Tem procurado matricular os professores na (AEE) isto quer dizer, no Atendimento Educacional Especializado para que os professores se especializem. Assim, os professores sendo capacitados, eles irão disseminar informações em prol do tema em pesquisa.

Secretaria da Educação. 2. A secretaria de educação, tem feito um preparo melhor dos professores, como especializá-lo, para que possa colocar essas pessoas com deficiência, em pé de igualdade com as pessoas normais, pois o preconceito se trata de uma questão cultural, e só será erradicado através da propagação da informação como: encontros, palestras e seminários apresentados por professores capacitados.

Percebe-se que os professores têm buscado se capacitar em cursos especializados na inclusão das pessoas com deficiência. Desse modo, eles procuraram aprimorar os seus 
conhecimentos, buscando uma melhor maneira de propalar informações, objetivando suprimir o preconceito existente entre as pessoas.

Mantoan (2009) ressalta que o preconceito distancia as pessoas com deficiência a terem oportunidade de conhecer e conviver com outras pessoas ditas normais, perante a sociedade.

Para Sassaki (2010), a inclusão é um desafio diante a supressão do preconceito, pela qual se objetiva a construção de uma sociedade democrática, por onde possamos colaborar para a cidadania.

\section{Atividades desenvolvidas para pessoas com deficiência}

Professores. 1. Jogos, e atividades adaptadas para o desenvolvimento intelectual das pessoas com deficiência.

Secretaria da Educação. 2. Atividades como por exemplo: Jogos, atividades de raciocínio, treinamento labiais, dentre outras. A intenção em questão é, de estar trabalhando a mente, como também o corpo das pessoas com deficiência, objetivando assim, desenvolver suas habilidades, através da interação do professor especializado nessas atividades com o professor regular de ensino.

Contudo, fica evidente que as atividades desenvolvidas no projeto pedagógico pelos professores são: jogos e atividades lúdicas adaptadas para cada aluno com deficiência e suas especificidades. Em vista disso, estas adaptações feitas nas atividades, irão proporcionar uma atividade de distração ilimitada, não ficando restrito a um só aluno com deficiência, fazendo com que todos eles participem.

Ribeiro (2004), afirma que o uso de jogos de regras, contribuíram para desenvolvimento do caráter investigativo dos alunos com deficiência, e para o processamento de ensino e aprendizagem da matemática, na sala de aula.

Para Maluf (2008), as atividades lúdicas são importantes para o desenvolvimento potencial das pessoas com deficiência, fazendo com essas atividades desenvolvam o seu condicionamento físico, emocional, motor, cognitivo e social. 
Brasil (2001a), diz que o professor deve permitir que os alunos com deficiência, experimentem várias atividades lúdidas de aprendizagem, para que eles possam perceber o ambiente ao qual pertence.

\section{O papel da família relacionado à inclusão}

Professores. 1. Tem um papel importante, porque é a família que na verdade prepara as pessoas com deficiência, a lhe dar com o mundo externo, quer dizer, seus enfrentamentos.

Secretaria da Educação. 2. O papel da família é fundamental no processo educativo da pessoa com deficiência, porque muitas vezes, a própria família é a primeira que rotula a pessoa do tema em questão. Diante disso, a família tem que ser a primeira a ter o respeito a essas pessoas com deficiência, e procurar a defender elas perante a legislação que o protegem.

Nota-se que a família é essencial, na base do desenvolvimento do processo educativo das pessoas com deficiência. Consequentemente, a família é que vai preparar como também defender as pessoas com deficiência, para convivência em uma sociedade, apesar que às vezes, é a própria família que o afasta, dessa integração social.

Amorim (2012), salienta que, a família tem a obrigação de preparar o emocional das pessoas com deficiência, pois a família, é o primeiro meio que a pessoa com deficiência tem, no seu processamento de ensino e aprendizagem.

Conforme indica Serra (2010), ainda que cada membro da família vivencie em sua casa com uma pessoa deficiente, é inclusivamente a mãe que sofre por paralisara sua vida profissional em decorrência a incapacidade do filho.

\section{Avaliação do desenvolvimento da pessoa com deficiência}

Professores. 1. Os alunos devem ser avaliados de acordo com o seu grau de deficiência.

Secretaria da Educação. 2. Os alunos com deficiência, não pode ser avaliado igual a um aluno dito normal, porque as habilidades e competências dos alunos com deficiência, não se desenvolvem com tanta facilidade e rapidez, tornando coisas simples para um aluno normal ser complexos para alunos com deficiência. Então, a 
avaliação desses alunos com deficiência, terá paciência para avaliar o todo do aluno, desde o momento que ele ingressou na escola, até o seu dia de hoje, isto quer dizer, tudo que ele aprendeu do seu ingresso a sala de aula, até o dia de hoje.

Fica evidente que os alunos com deficiência, são avaliados diferentemente de um aluno dito normal, sendo assim os alunos com deficiência serão avaliados com o seu grau de deficiência, mostrando as suas habilidades desenvolvidas nas atividades em estudo.

Brasil (2006b), destaca que a avaliação dos alunos com deficiência se dará de acordo com as características e habilidades básicas que cada uma delas têm.

Naubauer (2000), assevera que o professor tem a função de mediador e facilitador do processamento de aprendizagem dos alunos com deficiência, cabe ao professor criar condições e adequá-las para avaliar o desenvolvimento do aluno.

Stainback (2004), complementa que a padronização do planejamento de ensino avaliativo e metódico, prejudica não só o movimento de inclusão, mas todo processo educacional, porque nem todos os alunos são iguais.

\section{Preparação dos professores e funcionários para lidar com pessoas deficiência}

Professores. 1. Fazendo cursos de formação especializada na inclusão de pessoas com deficiência, para que as pessoas envolvidas no tema em questão, possam dar o melhor no serviço realizado.

Secretaria da Educação. 2. Através da formação, capacitando professores e funcionários para desmistificar a questão do preconceito que há, da pessoa com deficiência. Então, essa formação tem que começar desde o porteiro que recebe a pessoa com deficiência na entrada da escola até chegar nos demais funcionários como professores, diretor, secretários, coordenadores, e etc.

Nota-se que a capacitação dos professores e funcionários através de cursos especializados na inclusão das pessoas com deficiência, é o meio mais eficaz, para preparar as pessoas envolvidas no contexto. E desse modo, vai preparar do porteiro ao professor e as demais pessoas no envolvidas no enunciado.

Brasil (2000b), tendo em vista a garantia da educação das pessoas com deficiência, as ações educacionais têm caracterizado os esforços de sensibilização e progresso dos 
treinamentos na comunidade escolar, englobando a estrutura do processamento do ensinoaprendizado.

Castanha e Freitas (2006), afirmam que não basta só as políticas públicas voltadas ao ensino, mas ações públicas compartilhadas que oriente e qualifique os educadores e funcionários na formação de sujeitos, para valorizar a diversidade e fazer valer o sentido de inclusão.

Alves (2009), reitera que o importante não é só preparar os professores, mas todos os envolvidos no processo de ensino e aprendizagem das pessoas com deficiência, porque todos os profissionais envolvidos qualificados, servirão para promover melhorias no sentido de implantação de escolas inclusivas.

\section{Formação dos professores na área}

Professores. 1. Nem sempre os professores que estão trabalhando com a área de inclusão, têm uma formação específica. Às vezes, é preciso usar um professor regular e outro especializado.

Secretaria da Educação. 2. Não, porque nem todos os professores que estão envolvidos na inclusão das pessoas com deficiência, têm especialização, principalmente naquela área específica da deficiência da pessoa em questão, pois alguns dos envolvidos são contratados e estão ainda cursando a graduação.

Percebe-se que nem todos os docentes, têm uma formação especializada no assunto em questão. Desse modo, para suprir essa necessidade, às vezes, tem-se que fazer uma interação entre o professor regular e um outro professor especialista.

Glat e Blanco (2007), a incumbência pela resposta da educação na escola a ser dada para as pessoas com deficiência, serão de responsabilização dos profissionais, professores e apoio especializado.

Lima (2002), diz que muitos dos professores sem especialização se sentem inseguros e ansiosos, quando recebem em sua sala de aula pessoas com deficiência. 
Materiais tecnológicos para o desenvolvimento do conhecimento das pessoas com deficiência

\begin{abstract}
Professores. 1. Fazemos sim, aqui em Juazeiro na rede municipal de ensino, têm escolas com materiais tecnológicos como computadores, notebooks, além de outros recursos que são usados para desenvolver os conhecimentos das pessoas com deficiência.

Secretaria da Educação. 2. Sim, hoje o Ministério de Educação (MEC), tem enviado para escolas: computadores, máquinas de braile, máquinas de datilografia em braile, além de outros recursos para facilitar o desenvolvimento das pessoas com deficiência. Desse modo, computadores como outros recursos, são totalmente adaptados, para quaisquer tipos de deficiência.
\end{abstract}

É notória aqui nessa questão, que as escolas envolvidas com a inclusão das pessoas com deficiência, fazem o uso de materiais tecnológicos para o desenvolvimento e aprendizagem dessas pessoas. Em vista disso, podemos explicar: computadores, máquinas de braile notebooks dentre outros recursos.

Mantoan (2003), a educação atual, nos proporciona novos desafios, que estabelecem possibilidades mais adequadas, para compreender a diversidade das pessoas que a formam.

Bersch (2008), afirma que as tecnologias assistivas, como também as tecnologias da informação, vieram para integrar estrategicamente a estimulação dos processamentos intelectivos.

Moore e Kearsley (2007), cita que a tecnologia não irá resolver todos os problemas dos alunos com deficiência, mas ajudará resolver muitos deles.

Considerando as respostas dos professores entrevistados, num total de quatro, às perguntas fechadas do questionário, as quais permitiram respostas dicotômicas do tipo sim ou não, obtivemos os seguintes resultados.

A seguir, as respostas dos professores sobre as questões propostas foram dispostas na Tabela 1, a seguir: 
Tabela 1 - Respostas dos professores sobre as questões propostas

a) Aquisição do conhecimento na escola, por parte dos alunos com deficiência

\begin{tabular}{|c|c|c|}
\hline SIM & 3 & $75 \%$ \\
\hline $\mathrm{NA \tilde {O }}$ & 1 & $25 \%$ \\
\hline \multicolumn{3}{|c|}{ b) Os alunos com deficiência dificultam a qualidade do ensino } \\
\hline SIM & 1 & $25 \%$ \\
\hline $\mathrm{NA \tilde {O }}$ & 3 & $75 \%$ \\
\hline \multicolumn{3}{|c|}{ c) A eficácia da educação inclusiva na cidade de Juazeiro } \\
\hline SIM & 3 & $75 \%$ \\
\hline $\mathrm{N} \tilde{\mathrm{A} O}$ & 1 & $25 \%$ \\
\hline \multicolumn{3}{|c|}{ d) Escolas ou cursos profissionalizantes na cidade de Juazeiro } \\
\hline SIM & 2 & $50 \%$ \\
\hline $\mathrm{NÃO}$ & 2 & $50 \%$ \\
\hline \multicolumn{3}{|c|}{$\begin{array}{l}\text { e) Preconceito e discriminação dos alunos normais em relação } \\
\text { aos alunos com deficiência }\end{array}$} \\
\hline SIM & 1 & $25 \%$ \\
\hline NÃO & 3 & $75 \%$ \\
\hline
\end{tabular}

Fonte: Dados da Pesquisa, 2017.

Na questão a), os dados mostram que $75 \%$ dos professores entrevistados acham que sim, que as pessoas com deficiência, mesmo com todas as dificuldades que eles têm, seja no desenvolvimento dos seus conhecimentos ou em suas habilidades físicas, eles aprendem sim, no convívio numa escola com pessoas normais. Além do mais, ambos aprendem com essa convivência, fazendo com que isso quebre o preconceito existente diante do convívio entre eles.

Faleiros (2001), em seu estudo de educação inclusiva, abordando a temática de inclusão na escola, foi verificado que os alunos com deficiência, tiveram rendimentos tanto na sua socialização, quanto na sua aprendizagem.

Miranda (2001), salienta que pensar em uma escola inclusiva, é pensar em uma escola em que cada aluno, seja atendido de acordo com a sua especificidade, através de recursos metodológicos, que propicie o seu processo de aprendizagem e desenvolvimento. 
No quesito b), 75\% dos professores disseram que não, que as pessoas com deficiência não dificultam o ensino em uma sala de aula, pelo contrário eles agregarão mais conhecimentos, isto quer dizer, a partir do momento que os professores traçam uma metodologia de ensino para o desenvolvimento desses alunos, os alunos normais também irão ajudar nessa interação de aprendizagem, fazendo com que essa relação desenvolvam um conhecimento mútuo entre eles, enriquecendo mais o ensino abordado.

A aplicação de estratégias educativas diferenciadas, pode ser considerada como um método que possibilite o ingresso de todos os alunos ao conhecimento e é citada por Braccialli e Paiva (2010); Manzini e Santos (2002); Almirall, Soro-Camats e Bultó (2003); Manzini e Deliberato (2004).

Solé (1999) e Carline (2004), avistam que as estratégias como: planejamento de aula, apresentação de ideias, aula expositiva, pesquisas projetos dentre outros, podem ser aplicados por qualquer professor, para o alcançar todos os alunos em um processo de aprendizagem.

Na questão c), os dados mostram que $75 \%$ dos professores indagados, disseram que sim, que a cidade de Juazeiro da Bahia, a educação inclusiva relacionado as pessoas com deficiência, tem se desenvolvido bastante, e que a Secretaria de Educação e Esporte (SEDUC), em face com Núcleo de Atendimento Psicossocial e Inclusão (NAPSI) vem desenvolvendo projetos educacionais sobre a educação inclusiva, e tendo um efeito satisfatório, a respeito do tema demandado.

Rodrigues (2005), afirma que a educação para os alunos com deficiência, exige que o docente domine concomitantemente tecnologias e conhecimentos, que possibilite a qualquer aluno a uma condição de aprendizagem.

Ferreira e Ferreira (2004), complementam que a inclusão, não pode ser considerado como solução mágica, mas como desafio que exige alterações substanciais na escola, as práticas educativas, a convivência.

Para Kupfer (2002), destaca que o atual planeamento de inclusão exige alteração brusca na ideologia que fundamentam a escola.

Quanto a questão d), os dados levantados nesta questão, demonstraram um equilíbrio, mostrando que $50 \%$ dos professores entrevistados disseram que sim, que Juazeiro tem escolas ou cursos profissionalizantes. Contrapondo a isso, 50\% dos professores questionados, disseram o oposto, que Juazeiro não tem escolas ou cursos profissionalizantes. Em vista disso, 
as pessoas com deficiência, que acabam se prejudicando por não ter, uma informação exata sobre os cursos de capacitação efetivados na região.

Pesquisas apontam que o desenvolvimento profissional das pessoas com deficiência, no Brasil, dá-se por meio de projetos desenvolvidos por oficinas educativas (CABRAL, 2007; FERNANDES; NOMA, 2008; SILVA, 2008; TANAKA; MANZINI, 2005).

Entretanto, para Carretta (2004), apesar de os projetos de profissionalização reconhecer a possibilidade de trabalho da pessoa com deficiência, de fato, o reconhecimento não garante o seu ingresso no mercado de trabalho.

No que se refere a discriminação, na questão e), $75 \%$ dos professores entrevistados disseram que não há, discriminação dos alunos ditos normais relacionados aos com deficiência. Diante disso, os professores relatam que a interação entre ambos os alunos, têm criado uma base coesa, fortalecendo o laço de amizade entre eles, que só uma escola constrói.

Santos (2001), salienta que muitas pessoas entendem que é erroneamente a inclusão como simples procedimento de colocar pessoas ditas normais, com pessoas com deficiência.

Para Mantoan (2006), a inclusão escolar está relacionada a convivências democráticas, propondo uma diversidade de procedimentos como forma de compensar a igualdade que foi rompida por formas segregadas de ensino.

\section{Considerações Finais}

O desenvolvimento desse estudo possibilitou uma análise da Educação Inclusiva na Rede Municipal de Juazeiro, Bahia o qual permitiu concluir, através dos seus resultados, que a inclusão existe, porém não atende à todas as necessidades apresentadas pelas pessoas com deficiência. Desse modo, vale ressaltar a importância da interação entre a família, professores e alunos para inclusão dessas pessoas na rede educacional de ensino. De um modo geral, a Secretaria de Educação e Juventude (SEDUC) de Juazeiro/BA, tem demostrado apoio a Educação Inclusiva no município, dando-lhe suporte e aparato para o desenvolvimento da inclusão das pessoas com deficiência em uma sala de aula, objetivando assim, atender a demanda dessas pessoas. Desta forma, a (SEDUC), tem atribuído aos professores de Atendimento Educacional Especializado (AEE) pertencente a esta secretaria, uma parceria 
com o ensino regular, visando facilitar a construção no processo de ensino e aprendizagem das pessoas com deficiência.

Contudo, a pesquisa mostra que a convivência das pessoas com deficiência, junto a família e professores, ainda é um obstáculo a ser quebrado. Em vista disso, os familiares têm procurado se informar mais sobre o tema pesquisado, no intuito de sanar esta questão. Do mesmo modo, os professores para sanar essa barreira, têm feitos cursos especializados, visando capacitar-se no contexto, para atender as necessidades específicas, das pessoas com deficiência. Além disso, as famílias buscando informações como também os professores se capacitando, sobre o tema, fica mais fácil combater o preconceito existente, relacionado a inclusão das pessoas com deficiência, em uma sala de aula.

Em um processo pedagógico, onde a interação social entre a família, professores e alunos são destaques, esse processo irá trabalhar na formação do desenvolvimento dos instrumentos e atividades adaptadas como: gincanas, jogos, oficinas, livros em braile, computadores, dentre outros, para o desenvolvimento das habilidades das pessoas com deficiência em uma sala de aula.

Portanto, espera-se que a educação inclusiva fortaleça os laços entre as pessoas normais e as pessoas com deficiência, constituindo uma escola que agregue a igualdade, a dignidade e o respeito dentre eles. De fato, sugira-se que os docentes implementem projetos pedagógicos, objetivando estimular o desenvolvimento do aluno na educação inclusiva e a sua integração perante a sociedade.

\section{Referências}

MIRANDA, Teresinha Guimarães; GALVÃO FILHO, Teófilo Alves (org.). O professor e a educação inclusiva: formação, práticas e lugares. Salvador: EDUFBA, 2012.

COSTA, Valdelúcia Alves da. Formação de Professores e Educação Inclusiva: Experiências na Escola Pública. In: COSTA Valdelúcia Alves da.; CARVALHO, Mariza Borges Wall B. de.; MIRANDA, Teresinha Guimarães \& DAMASCENO, Allan (Orgs). Políticas Públicas e Produção do Conhecimento em Educação Inclusiva. Niterói: Intertexto Editora X CAPES, 2011. 
ZOÍA, A. Todos iguais, todos desiguais. In: ALMEIDA, D. B. de (Org). Educação: diversidade e inclusão em debate. Goiânia: Descubra, 2006.

MARCONI, Marina de Andrade; LAKATOS, Eva Maria. Técnicas de pesquisa: planejamento e execução de pesquisas, amostragens e técnicas de pesquisas, elaboração, análise e interpretação de dados. 7 ed. São Paulo: Atlas, 2008.

GIL, Antônio Carlos. Métodos e Técnicas de Pesquisa Social. 6 ed. São Paulo: Atlas 2010.

Brasil. Decreto ${ }^{\circ}$ 3.298, de 20 de dezembro de 1999. Regulamenta a Lei $\mathrm{n}^{\mathrm{o}} 7.853$, de 24 de outubro de 1989, dispõe sobre a política nacional para a integração da pessoa portadora de deficiência, consolida as normas e dá outras providências. Diário Oficial da União, DF, 21 dez. 1999. Disponível em: <http://www.planalto.gov.br/ CCIVIL/decreto/D3298.htm>. Acesso em: 23 jan. 2017.

Disponível em: <http://www.pessoacomdeficiencia.gov.br/app/conade/sobre-oconade/regimento-interno>. Acesso em: 23 jan. 2017.

PAULON, S. M; FREITAS, L. B. L; PINHO, G. S. Documento subsidiário à política de inclusão - Brasília: Ministério da Educação, Secretaria de Educação Especial, 2005.

GIL, Marta. Educação Inclusiva: o que o professor tem a ver com isso? Universidade de São Paulo: Ashoka Brasil, 2005.

BRASIL. Constituição (1988). Constituição da República Federativa do Brasil: promulgada em 5 de outubro de 1988: atualizada até a Emendas Constitucionais de n. 1, de 1992, a 53, de 2006, e pelas Emendas Constitucionais de Revisão de n. 1 a 6, de 1994. - 27. ed. - Brasília: Câmara dos Deputados, Coordenação de Publicações, 2007.

CARDOSO, M. Aspectos históricos da educação especial: da exclusão à inclusão - uma longa caminhada. In: MOSQUERA, J.; STOBAÜS, C. (orgs.). Educação especial: em direção à educação inclusiva. Porto Alegre: EDIPUCRS, 2004.

BOOTH, T.; AISNCOW, M. Index para a inclusão: Desenvolvendo a aprendizagem e a participação nas escolas. $3^{\circ}$ Ed. Reino Unido: CSIE.2011.

Convenção sobre os Direitos das Pessoas com Deficiência: Protocolo Facultativo à Convenção sobre os Direitos das Pessoas com Deficiência: Decreto Legislativo $\mathrm{n}^{\mathbf{0}}$ 186, de 09 de julho de 2008: Decreto $\mathrm{n}^{\mathrm{o}}$ 6.949, de 25 de agosto de 2009. $4^{\mathrm{a}}$ Ed., rev. e atual. Brasília: Secretaria de Direitos Humanos, 2010.

Lakatos, Eva Maria. Fundamentos de metodologia científica, Marina de Andrade Marconi, Eva Maria Lakatos. - 5. ed. - São Paulo: Atlas 2003.

CROCHÍK, José Leon. Preconceito e Educação Inclusiva. CROCHÍK, José Leon (Coordenador) - Brasília: SDH/ PR, 2011. 
BRASIL. Lei No 13.146, de 6 de julho de 2015. Institui a Lei Brasileira de Inclusão da Pessoa com Deficiência (Estatuto da Pessoa com Deficiência). Diário Oficial da União, 7 jul. 2015. ALVES F. Inclusão: muitos olhares, vários caminhos e um grande desafio. Rio de Janeiro, WAK EDITORA, 2009.

LIMA PA. Educação Inclusiva e igualdade social. São Paulo; AVERCAMP, 2002.

BERSCH, Rita. Introdução à tecnologia assistiva. Porto Alegre: Centro Especializado em Desenvolvimento Infantil [CEDI], 2008.

LIPOVETSKY, Gilles. A Era do Vazio. Barueri: Manole, 2005.

SAAD, S. N. Preparando o caminho para a inclusão: dissolvendo mitos e preconceitos em relação à pessoa com síndrome de Down. São Paulo: Vetor, 2003.

VOIVODIC, M. A. Inclusão escolar de crianças com síndrome de Down. Rio de Janeiro: Vozes, 2007.

SASSAKI, Romeu Kazumi. Inclusão: construindo uma sociedade para todos. 8. ed. Rio de Janeiro: WVA, 2010.

A formação de professores para a inclusão de alunos no espaço pedagógico da diversidade. In: MANTOAN [et al]. O desafio das diferenças nas escolas. Rio de Janeiro: Vozes, 2009.

MALUF, A. C. M. Atividades lúdicas para educação infantil: Conceitos, orientações e prática. RJ: Vozes, 2008.

BRASIL. Ministério da Educação. Secretaria de Educação Especial. Avaliação: políticas e programas governamentais em educação especial. Educação para todos - EFA 2000. Disponível em: <http://www.mec.gov.br/seesp/publicacoes.shtm>. Acesso em 14 mai. 2000b.

- Programa de Capacitação de Recursos Humanos do Ensino Fundamental: deficiência visual. Vol 1. Brasília: Ministério da Educação, Secretaria de Educação Especial, 2001a.

MANTOAN, M. T. E. Inclusão escolar: o que é? por quê? como fazer? São Paulo: Moderna, 2003.

SERRA, Dayse. Autismo, família e inclusão. Polemica. Universidade do Estado do Rio de Janeiro, Rio de Janeiro, 2010.

AMORIM, Marcia Camila Souza de; NAVARRO Elaina Cristina. Afetividade na educação infantil. Interdisciplinar: Revista Eletrônica da Univar (2012). 
CASTANHO, D. M.; FREITAS, S. N. Inclusão e prática docente no ensino superior. Revista Educação Especial, Santa Maria, n. 27, 2006.

GLAT, R.; BLANCO, L. M. V. Educação especial no contexto de uma educação inclusiva. In: GLAT, R. (Org.). Educação inclusiva: cultura e cotidiano escolar. Rio de Janeiro: Ed. 7 Letras, 2007.

CABRAL, N. Educação profissional a pessoa com deficiência e o mundo do trabalho. In: SEMINÁRIO NACIONAL - ESTADO E POLÍTICAS SOCIAIS NO BRASIL, 3, 2007, Cascavel, PR. Democracia e políticas sociais. Disponível em: $<$ http://cacphp.unioeste.br/projetos/gpps/midia/seminario1/trabalhos/Educacao/eixo6/17nelso ncabral.pdf $>$. Acesso em: 07 de jul. 2017.

CARRETTA, R.Y.D. Pessoas com deficiência organizando-se em cooperativas: uma alternativa de trabalho? 2004. 173 p. Tese (Doutorado em Engenharia de Produção) Universidade Federal de São Carlos, São Carlos, 2004.

FERNANDES, O.A.; NOMA, A.K. Educação, trabalho e inclusão social: interface entre educação profissional e educação especial no Brasil a partir de 1990. In: SEMINÁRIO DO TRABALHO, 2008.

TANAKA, E.D.O.; MANZINI, E.J. O que os empregadores pensam sobre o trabalho da pessoa com deficiência? Revista Brasileira de Educação Especial, Marília, v. 11, n. 2, p. 273$294,2005$.

SILVA, I.M.A. Políticas de Educação Profissional para a pessoa com deficiência. In: REUNIÃO ANUAL DA ASSOCIAÇÃO NACIONAL DE PÓS-GRADUAÇÃO E PESQUISA EM EDUCAÇÃO, 31, 2008, Caxambu. Constituição brasileira, direitos humanos e educação. Disponível em: <http://www.anped.org.br/reunioes/31ra/2poster/GT15-4258--Int.pdf>. Acesso em: 07 de jul.2017.

STAINBACK, S.B. Entrevista concedida à Pátio Revista Pedagógica. Pátio Revista Pedagógica, ano VIII, no 32, novembro de 2004/janeiro de 2005, Artmed Editora, 2004.

Miranda, M. J. de (2001). Educação, deficiência e inclusão no município de Maringá. Dissertação de Mestrado não publicada, Universidade Estadual de Maringá, Maringá, PR.

Faleiros, M. H. S. (2001). A inclusão de alunos com deficiência mental na perspectiva de suas professoras e produções acadêmicas. Dissertação de Mestrado não publicada, Universidade Federal de São Carlos, São Carlos, SP.

Santos, M. S. (2001). O desafio de uma experiência. Em M. T. E. Mantoan (Org), Caminhos pedagógicos da inclusão, São Paulo: Memnon. 
ALMIRALL, C.B.; SORO-CAMATES, E.; BULTÓ, C.R. Sistemas de sinais e ajudas técnicas para comunicação alternativa e escrita: princípios teóricos e aplicações. São Paulo: Santos, Livraria Editora, 2003.

BRACCIALLI, L.M.P.; PAIVA, P.C. Textura do recurso pedagógico e implicações em atividades de encaixe realizada por indivíduos com Paralisia Cerebral. Revista Brasileira de Educação Especial, v.15, n.2, p.1.2010.

CARLINI AL. E agora: preparar a aula. In: SCARPATO, M. (Org.). Os procedimentos de ensino fazem a aula acontecer. São Paulo: Avercamp; 2004.

MANZINI, E.J. SANTOS, M.C.F. Portal de ajudas técnicas para educação: equipamento e material pedagógico para educação, capacitação e recreação da pessoa com deficiência física: recursos pedagógicos adaptados. Brasília: MEC: SEESP, 2002, fascículo 1.

MANZINI, E.J. DELIBERATO, D. Portal de ajudas técnicas: equipamentos e material pedagógico para educação, capacitação e recreação da pessoa com deficiência física: recursos para comunicação alternativa. Brasília: MEC: SEESP, 2004, v.2.

SOLÉ L. Aprender e ensinar na educação infantil. Porto Alegre: Artmed; 1999.

MANTOAN, Maria Teresa Eglér. Igualdades e diferenças na escola: como andar no fio da navalha. IN: ARANTES, Valéria Amorim (org.). Inclusão escolar: pontos e contrapontos. São Paulo: Summus, 2006.

FERREIRA, M. C.; FERREIRA, J. R. Sobre inclusão, políticas públicas e práticas pedagógicas. São Paulo: Autores associados, 2004.

KUPFER, M. C. Por que ensinar a quem não aprende. In: Psicanálise, infância, educação. ANAIS DO III COLÓQUIO DO LEPSI, 2002.

RODRIGUES, D. Educação e diferença, valores e prática para uma educação inclusiva. Porto: Porto Editora, 2005.

NEUBAUER, Rose. Quem tem medo da progressão continuada? Ou melhor, a quem interessa o sistema de reprovação e exclusão social? Secretaria da Educação, São Paulo. http://novaescola.abril.com.br/estante/quemtem.doc. 2000.

RIBEIRO, E. F. F. O ensino da matemática por meio de jogos de regras. 2004. 13p. Artigo (Licenciatura em Matemática). Universidade Católica de Brasília, Brasília, 2004.

BRASIL. Ministério da Educação. Secretaria de Educação Especial. Saberes e práticas da inclusão. Avaliação para identificação das necessidades educacionais especiais. Brasília, 2006b. 
Id on Line Revista Multidisciplinar e de Psicoloqia

Id on Line Multidisciplinary and Psycology Journal

MOORE, Michael G.; KEARSLEY, Greg. Educação a distância: uma visão integrada Edição especial ABED - Associação Brasileira de Educação a Distância. São Paulo: Thomson Learning, 2007.

Como citar este artigo (Formato ABNT):

AGUIAR, Francisco C.; FERREIRA, Leide J.C.; ROSA, Adilton M.; FERREIRA, Willian C.; ALEXANDRE, Lucimara A.C. A Educação Inclusiva na Rede Municipal em Juazeiro da Bahia. Id on Line Revista Multidisciplinar e de Psicologia, Maio de 2017, vol.11, n.37, p.46-65. ISSN: 1981-1179.

Recebido: 01.08.2017;

Aceito: 09.08 .2017 